\title{
In Situ Survival of Genetically Engineered Microorganisms in a Tropical Aquatic Environment
}

\author{
A. J. Alvarez, G. M. Yumet, and C. L. Santiago
}

Department of Biology, P.O. Box 23360, University of Puerto Rico, Rio Piedras, Puerto Rico 00931-3360

T. C. Hazen

Savannah River Laboratory, Environmental Sciences Division, Aiken, South Carolina 29808

R. Chaudhry

Department of Biological Science, Oakland University, Rochester, Michigan 48309

G. A. Toranzos ${ }^{* 1}$

Department of Biology, P.O. Box 23360, University of Puerto Rico, Rio Piedras, Puerto Rico 00931-3360

In this study, the survival of genetically engineered microorganisms (GEMs) and their interactions with the environmental microbiota of a tropical river was investigated. Diffusion chambers were used for the in situ survival experiments with a nonplasmid containing Escherichia coli $\mathrm{DH} 1$ strain and two model GEMs, E. coli JM103 containing a 2.6 kilobase plasmid (pUC9) and E. coli DH1 with a $4.8 \mathrm{~kb}$ plasmid ( $p$ WTAla5'). Pure culture survival studies indicated that after a week in the environment a $1.0 \log _{10}$ decrease in bacterial numbers occurred for both $E$. coli DH1, while a $3.0 \log _{10}$ reduction was observed for $E$. coli JM103. However, a reduction of $4.0 \log _{10}$ was observed for the E. coli DH1 (pWTAla5') when placed in a chamber conjointly with the resident microbiota. The data suggest that the presence of a plasmid makes no difference on the survival time of GEMs, whereas the presence of competing bacteria is ultimately what limits the survival time of GEMs in the environment. (c) 1996 by John Wiley \& Sons, Inc.

\section{INTRODUCTION}

An accidental or deliberate release of genetically engineered microorganisms (GEMs) into the environment can be a possible source of biological contamination of ground or surface waters. Although there seem to be many promising applications of GEMs in agriculture, industry, and medicine, their use has been limited so far by environmental concerns (Bentjen et al., 1989).

\footnotetext{
* To whom correspondence should be addressed.
}

Fundamental concerns regarding GEMs in the environment include the ability of these organisms to survive, to compete with the indigenous microbiota, and the possible transfer of their manipulated DNA to other microorganisms. Prediction of the fate of the GEMs and their engineered DNA in natural systems is a major component of a complete risk assessment process (Cuskey, 1990).

Previous work in our laboratory has shown the efficacy of using in situ diffusion chambers for bacterial survival. Some of these studies have been conducted with diverse eukaryotic and prokaryotic microorgan- 
isms such as Escherichia coli (Carrillo et al., 1985), Klebsiella (Lopez et al., 1988), and Aeromonas (Biamon and Hazen, 1983). These studies were conducted under various environmental conditions, in areas polluted by pulp mill, rum distillery, as well as domestic and industrial sewage effluents. The use of these chambers allows for the diffusion of soluble salts as well as organic material while preventing the escape of bacteria even after these have undergone morphological changes to become ultramicrocells in response to nutrient limitation.

By using diffusion chambers it is possible to expose microorganisms to environmental conditions without an actual release. This allows us to determine the survival time of the exposed microorganisms and their confinement allows for studies regarding the possible transfer of the manipulated nucleic acid to the indigenous microflora. The purpose of this study was to determine the survival rates and potential for gene transfer of two model GEMs organisms and a nonplasmid-containing strain.

\section{MATERIALS AND METHODS}

\section{Bacterial Strains}

Strains used in this study as model for GEMs were as follows: (1) E. coli DH1 containing the pWTAla5' plasmid. This is a 4.8 kilobase $(\mathrm{kb}) \mathrm{pBR} 322$ derivative that contains a 437 base-pair (bp) sequence coding for the tRNA ${ }^{\text {ala }}$ gene isolated from Bombyx mori (Larson et al., 1983). (2) Escherichia coli JM 103 containing the pUC9 plasmid, a $2.6 \mathrm{~kb}$ plasmid which contains a 147 bp U1snRNA gene coding insert from the sea urchin Lytechinus variegatus (Morris and Marzluff, 1985). (3) A nonplasmid containing $E$. coli DH1.

\section{In Situ Survival of GEMs}

In situ survival experiments were carried out in the La Mina River located in the Caribbean National Rain Forest of "El Yunque," using survival chambers (McFeters and Stuart, 1972). The river, characterized by pristine waters, begins at an elevation of about $1000 \mathrm{~m}$ above sea level, in the Palma Sierra forest, and receives about $762 \mathrm{~cm}$ of rain each year (Lopez et al., 1988). In situ studies were conducted during the months of November and January. Each plexiglass diffusion chamber has a capacity greater than $100 \mathrm{~mL}$. The diffusion surface was created by a $0.45 \mu \mathrm{m}, 142 \mathrm{~mm}$ diameter, Nylon reinforced Versapor 450 membrane filter (Gelman, Ann Arbor, MI). All strains were grown in luria broth at $37^{\circ} \mathrm{C}$ and harvested at midlog phase. Sterile chambers were loaded with a concentration of $10^{9}$

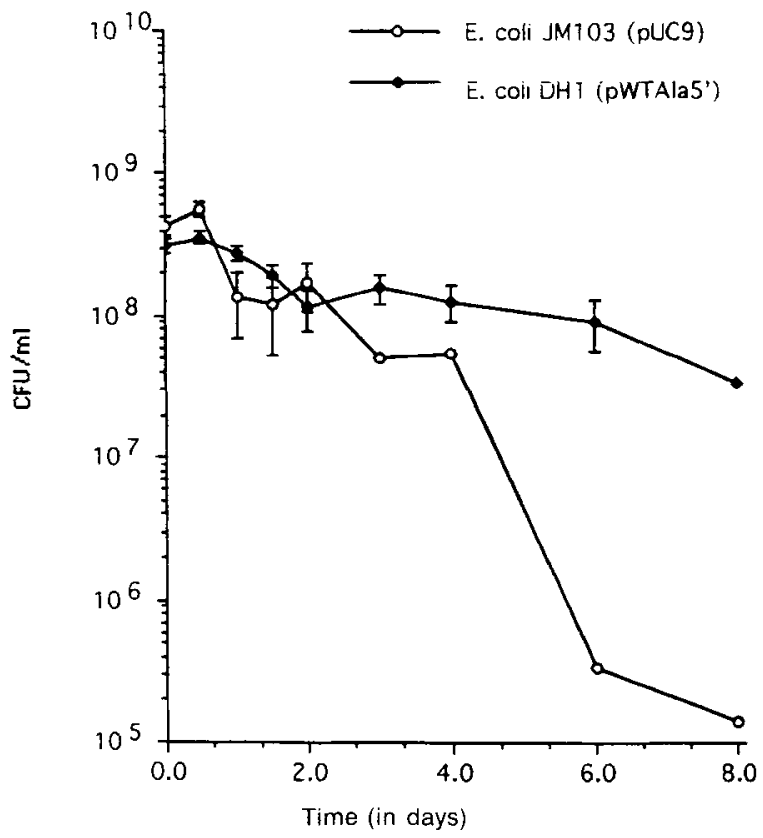

Fig. 1. In situ survival of Escherichia coli JM103 (pUC9) and $E$. coli DH1 (pWTAla5') in the La Mina River. Each strain was loaded in pure culture $\left(10^{\circ} \mathrm{CFU} / \mathrm{mL}\right)$ in separate diffusion chambers and sampled at increasing intervals to measure bacterial decay. Data are expressed as the mean \pm standard error.

colony forming units (CFU)/mL, and were sampled at increasing selected time intervals to determine its survival time, estimated time to decrease by $90 \%$, or one order of magnitude (Jimenez et al., 1989). Each trial consisted of duplicate chambers and was repeated at least twice.

Viable count methods were used to determine bacterial concentrations (American Public Health Association, 1985). The possible exchange of recombinant plasmids between GEMs and the resident microflora was monitored by antibiotic-containing selective media and nucleic acid probes using colony hybridization (Sambrook et al., 1989). Samples from each diffusion chamber were plated and incubated at $37^{\circ} \mathrm{C}$. Colonies were replica-transferred onto nitrocellulose, and cells were lysed by alkali treatment and processed for hybridization (Sambrook et al., 1989; Toranzos and Alvarez, 1989). After hybridization and high stringency washes, hybridized signals were detected by autoradiography.

\section{RESULTS AND DISCUSSION}

In the first survival experiment $10^{9} / \mathrm{CFU} / \mathrm{mL}$ of the GEMs strains $E$. coli DH1 (pWTAla5') and $E$. coli JM103 (pUC9) were loaded as pure cultures into sepa- 


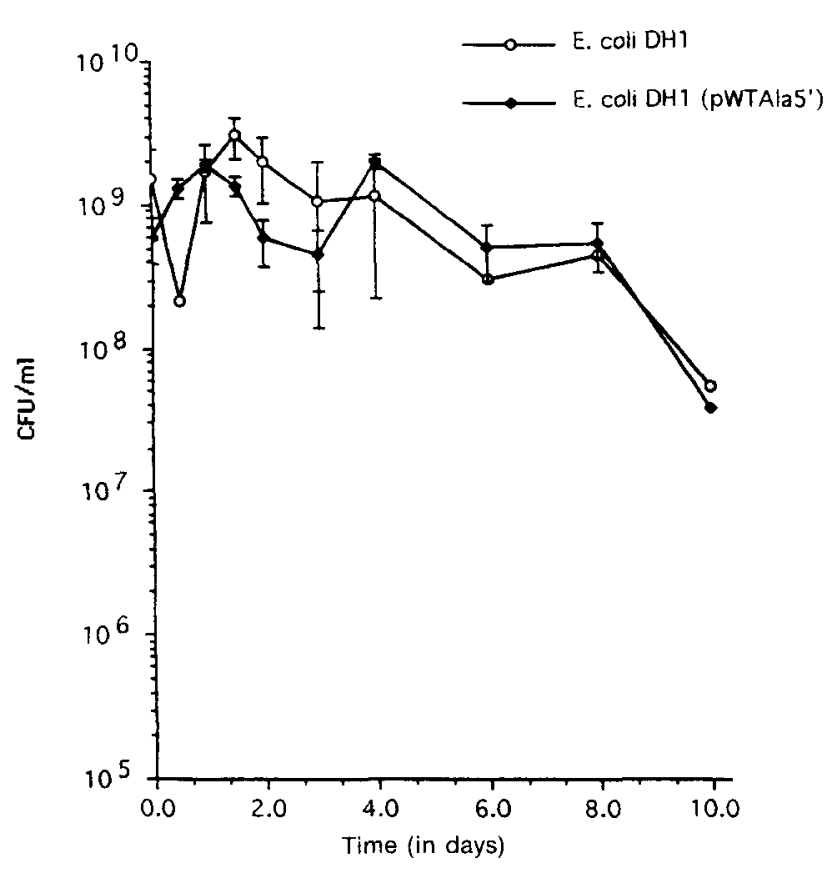

Fig. 2. In situ survival of $E$. coli $\mathrm{DH}_{1}$ and $E$. coli $\mathrm{DH} 1$ (containing pWTAla5') in the La Mina River. Each strain was loaded in pure culture $\left(10^{9} \mathrm{CFU} / \mathrm{mL}\right)$ in separate diffusion chambers and sampled at increasing intervals to measure bacterial decay. Data are expressed as the mean \pm standard error.

rate chambers. Even though both are members of the same genus and species, they contain different plasmids. After eight days in the environment, results showed that one of the GEMs survived longer than the other (Fig. 1). A $3.0 \log _{10}$ decrease in bacterial numbers were observed for $E$. coli JM103, while the $E$. coli DH1 showed a decrease of $1.0 \log _{10}$. These results seem to indicate that some GEMs are less likely to survive in the environment, diminishing the possibility of gene transfer from the GEMs to the resident microbiota.

In a second experiment, diffusion chambers were loaded with $E$. coli $\mathrm{DH} 1$ (pWTAla5 ${ }^{\prime}$ ) at $10^{9} \mathrm{CFU} / \mathrm{mL}$ and a nonplasmid containing $E$. coli $\mathrm{DH} 1$ strain. After a week in the environment under similar conditions a 10 -fold decrease in bacterial numbers was observed for both strains (Fig. 2). However, when both strains were loaded in different chambers containing water from the La Mina River study site (containing $10^{7} \mathrm{CFU} / \mathrm{mL}$ of indigenous bacteria), a 1000-fold reduction for the $\mathrm{DH} 1$ (pWTAla5') occurred, compared with a 10 -fold reduction for the nonplasmid-containing DH1 strain (Fig. 3). These results suggest that the presence of competing bacteria may limit the survival time of GEMs in the environment. In addition, there was no detectable transfer of genetic information from the GEMs to the resident microflora either by antibiotic resistance trac- ers or by colony hybridization using radioactively labeled specific probes (data not shown).

Releasing GEMs to the environment requires a clear understanding of their behavior and survival within a microbial community. The ability of GEMs to survive under environmental conditions has been reported elsewhere (Awong et al., 1990; Devanas and Stotzky, 1986; Winstanley et al., 1991). The present study indicates that two strains of GEMs exhibit different survival patterns under the same environmental conditions in spite of the fact that both are members of the genus Escherichia. These bacteria contain different plasmids (pUC9 and pWTAla5') that endow them with different properties. Plasmid size, antibiotic resistance, and plasmid copy number per cell are the most obvious differences between these plasmids. The presence of nonrequired plasmid DNA has been previously shown to affect the survival times of some bacteria in environmental studies (Jain et al., 1988). Results obtained in this study seem to fit the same pattern.

Differences in survival rates between these GEMs indicate that some GEMs are less resilient in the environment. This diminishes the possibilities of genetic transfer from the GEMs to the resident microflora. Our study showed no transfer of genetic information from the GEMs to indigenous microflora. Similar results

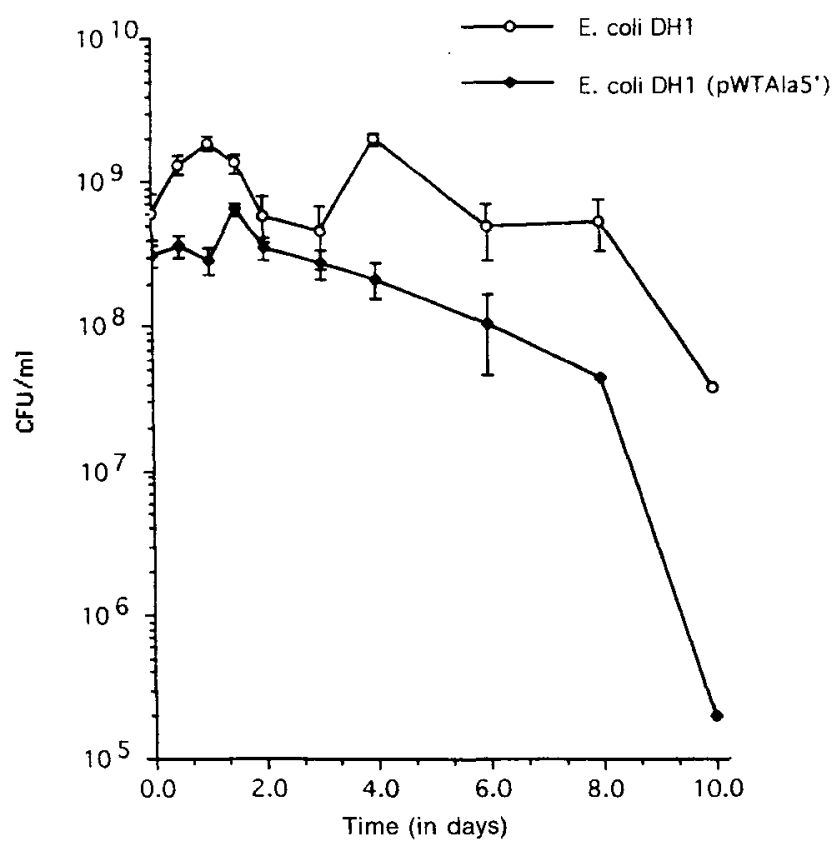

Fig. 3. In situ survival of E. coli $\mathrm{DH} 1$ and $E$. coli $\mathrm{DH} 1$ (pWTAla5') in the La Mina River. Each strain $\left(10^{9} \mathrm{CFU} /\right.$ $\mathrm{mL}$ ) was mixed with river water containing $10^{7} \mathrm{CFU} / \mathrm{mL}$ of naturally occurring bacteria, loaded in separate diffusion chambers, and sampled at increasing intervals to measure bacterial decay. Data are expressed as the mean \pm standard error. 
have been described previously (Devanas et al., 1986). This is to be expected, since both plasmids are nonconjugative and poorly mobilizable. This is one of the main reasons why they are used most often in genetic recombination experiments (Jain et al., 1988). This study indicates that the use of the least resistant strains and the least mobilizable plasmids should be used if they are to be released into the environment. Our results suggest that one should not try to predict survival times of a genetically engineered microorganism based on experiments conducted with another. Thus, GEMs must be evaluated on an individual basis prior to their release into the environment.

In order to determine if, in fact, the genetic differences contributed to the different survival times, in situ parallel experiments were run with a plasmid-containing and a plasmid-free strain. After a week in the environment in diffusion chambers, no differences in survival were observed between the plasmid-containing and plasmid-free strains. However, when both strains were exposed to resident microflora a significant difference in the survival time of the GEM (plasmidbearing strain) was observed.

Whereas our studies suggest that the presence of the plasmid makes no difference on the survival of the two strains under pure culture conditions, the presence of competing bacteria seems to be limiting their survival time in the environment. Similar results have been reported by Amy and Hiatt (1989) and Devanas et al. (1986), among others. Their studies have shown that, except in cases where the plasmid conferred a selective advantage, its presence had little effect on the survival of the bacterial host. In the presence of competing bacteria the plasmid may become a biosynthetic burden-hence, the plasmid-containing bacteria may be at a disadvantage. This proposal is based on studies in which cells exhibited an enhanced growth rate upon loss of their plasmid (Morgan et al., 1989).

Our observations contrast with those suggested by Marshall et al. (1988) and Awong et al. (1990), who indicated that the plasmid-containing GEMs survived better, or as well as their plasmid-free counterparts. These contradicting data indicate the need for further research on the survival of recombinant microorganisms, including strain-specific studies. These should be conducted under environmental conditions that simulate, as closely as possible, the environment into which they will be released. The advantages of using diffusion chambers are simplicity, ease in adjusting for environmental variables, and the fact that the organisms are continuously exposed to the test water.

In conclusion, in situ survival experiments demonstrated that GEMs must be evaluated individually if they are to be released into the environment, and that the presence of competing bacteria may ultimately limit the survival of genetically engineered microorganisms in the environment.

This work was supported in part by a RIMI grant (National Institutes of Health No. M32 89 1391), Industry University Research Center Grant No. G-91-02, and a SUBE National Institutes of Health Grant No. GM 08102.

\section{REFERENCES}

American Public Health Association. 1985. Standard Methods for the Examination of Water and Wastewater, 16th Edition. Washington, DC.

Amy, P. S., and H. D. Hiatt. 1989. Survival and detection of bacteria in an aquatic environment. Appl. Environ. Microbiol. 55:788-793.

Awong, J., G. Bitton, and G. R. Chaudhry. 1990. Microcosm for assessing survival of genetically engineered microorganisms in aquatic environments. Appl. Environ. Microbiol. 56:977-983.

Biamon, E. J., and T. C. Hazen. 1983. Survival and distribution of Aeromonas hydrophila in near-shore coastal waters of Puerto Rico receiving rum distillery effluent. Water Res. 17:319-326.

Carrillo, M., E. Estrada, and T. C. Hazen. 1985. Survival and enumeration of Bifidobacterium adolescentis and Escherichia coli in a tropical rain forest watershed. Appl. Environ. Microbiol. 50:468-476.

Cuskey, S. M. 1990. The use of lethal bacterial genes to limit survival of released genetically engineered microorganisms, p. 197-199. In Review of Progress in the Biotechnology-Microbial Pest Control Agent Risk Assessment Program, USEPA-R\&D, July.

Devanas, M. A., and G. Stotzky. 1986. Fate in soil of a recombinant plasmid carrying a Drosophila gene. Current Microbiol. 13:279-283.

Devanas, M. A., D. R. Eshkol, and G. Stotzky. 1986. Survival of plasmid-containing strains of Escherichia coli in soil: Effect of plasmid size and nutrients on survival of hosts and maintenance of plasmids. Curr. Microbiol. 13:269-277.

Jain, R. K., R. S. Burlage, and G. S. Sayler. 1988. Methods for detecting recombinant DNA in the environment. CRC Crit. Rev. Biotech. 8:33-85.

Jimenez, L., L. Muñiz, G. A. Toranzos, and T. C. Hazen. 1989. Survival and activity of Salmonella typhimurium and Escherichia coli in tropical freshwater. J. Appl. Bacteriol. 67:61-69.

Larson, D., J. Bradford-Wilcox, L. S. Young, and K. Sprague. 1983. A short 5' flanking region containing conserved sequences is required for silkworm alanine tRNA gene activity. Proc. Natl. Acad. Sci. USA 80:3416-3420.

Lopez, A. J., J. L. Prieto, and T. C. Hazen. 1988. Comparison of the in situ survival and activity of Klebsiella pneumoniaea and Escherichia coli in tropical marine environments. Microb. Ecol. 15:41-57. 
Marshall, B., P. Flynn, D. Kamely, and S. B. Levy. 1988. Survival of Escherichia coli with and without COLE1:Tn5 after aerosol dispersal in a laboratory and a farm environment. Appl. Environ. Microbiol. 54:1776-1783.

McFeters, G. A., and D. G. Stuart. 1972. Survival of coliform bacteria in natural waters: field laboratory studies with membrane-filter chambers. Appl. Environ. Microbiol. 24:805-811.

Morgan, J. A., C. Winstanley, R. W. Pickup, J. G. Jones, and J. R. Saunders. 1989. Direct phenotypic and genotypic detection of a recombinant pseudomonad population released into lake water. Appl. Environ. Microbiol. 55:2537-2544.

Morris, G. F., and W. F. Marzluff. 1985. Synthesis of U1 RNA in isolated nuclei from sea urchin embryos: U1 RNA is initiated at the first nucleotide of the RNA. Mol. Cell. Biol. 5:1143-1150.

Sambrook, J., E. F. Fritsch, and T. Maniatis. 1989. Molecular Cloning: A Laboratory Manual. Cold Spring Harbor Laboratory Press, Cold Spring Harbor, NY.

Sharples, F. E. 1983. Spread of organisms with novel genotypes: Thoughts from an ecological perspective. Recomb. DNA Tech. Bull. 6:43-56.

Toranzos, G. A., and A. J. Alvarez. 1992. Solid-Phase PCR for the detection of pathogens in water. Can. J. Microbiol. 38:365-369.

Winstanley, C., J. A. Morgan, R. W. Pickup, and J. R. Saunders. 1991. Use of a xy $1 \mathrm{E}$ marker gene to monitor survival of recombinant Pseudomonas putida populations in lake water by culture on nonselective media. Appl. Environ. Microbiol. 57:1905-1913. 